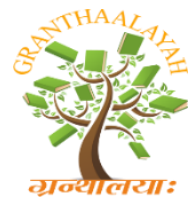

\author{
INTERNATIONAL JOURNAL OF RESEARCH - \\ GRANTHAALAYAH \\ A knowledge Repository
}

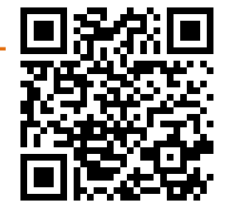

Science

\title{
DETERMINATION OF THERMAL CONDUCTIVITY FOR ADOBE (CLAY SOIL) MIXED WITH DIFFERENT PROPORTIONS OF QUARTZ (SHARP SAND)
}

\author{
S. K Singh ${ }^{1}$, Ngaram S. M. ${ }^{2}$, Wante H. P. ${ }^{3}$ \\ ${ }^{1}$ Department of Physics, Adamawa State University Mubi, Adamawa State, Nigeria. \\ ${ }^{2,3}$ Department of Science Laboratory Technology (Physics Unit), Federal Polytechnic Mubi, \\ Adamawa State, Nigeria.
}

\begin{abstract}
This research investigated the thermal conductivity of Adobe mixed with Quartz in view of their availability usage as building materials. The thermal conductivities of disc made from AdobeQuartz chippings were determined. The values of the thermal conductivities obtained were between $0.6 \mathrm{Wm}-1 \mathrm{k}-1$ and $0.9 \mathrm{Wm}-1 \mathrm{k}-1$, these values could be used to identify Adobe/Quartz as one of the engineering materials used in building construction. Adobe/Quartz was prepared in discs form of the same diameters and thicknesses and was also compressed under the same pressure of 15 atmospheres (100: 0, 95: 5and 80: 20). The average values of the thermal conductivities were between $0.07 \mathrm{Wm}-1 \mathrm{~K}-1$ and $0.93 \mathrm{Wm}-1 \mathrm{~K}-1$, for sample contained the proportion of $(80: 20)$ and the sample of ratio (95:5). MATLAB 7.0 and EXCEL software were used in the various computations, especially in determining dT/dt, Root mean square error (RMSE), Curve fittings parameter and the correlation coefficient, R2. An average correlation coefficient of 0.78 was existed between Adobe-Quartz ratio and thermal conductivity. The equation, $\mathrm{y}=-0.11 \mathrm{x} 2+0.01 \mathrm{x}$ +1.03 is the general equation that can be used for the prediction of average thermal conductivity at various ratios. Where $y$ is the average thermal conductivity and $x$ here signifies the ratios. This also indicates that compacted Adobe-Quartz of low density will be a suitable thermal insulator when used as aggregates in walls.
\end{abstract}

Keywords: Thermal Conductivity; Adobe; Quartz; Lee Disc and Resistivity.

Cite This Article: S. K Singh, Ngaram S. M., and Wante H. P. (2019). "DETERMINATION OF THERMAL CONDUCTIVITY FOR ADOBE (CLAY SOIL) MIXED WITH DIFFERENT PROPORTIONS OF QUARTZ (SHARP SAND)." International Journal of Research Granthaalayah, 7(3), 335-345. https://doi.org/10.29121/granthaalayah.v7.i3.2019.979.

\section{Introduction}

Thermal conductivity is a measure of a material ability to transport heat energy. It is an intrinsic property of any material. It is defined as the quantity of heat energy transmitted per unit distance per unit temperature change over that distance in the direction of heat transfer. It is highly 
dependent on the chemical composition, physical structure, and state of the materials. Because of its importance in characterizing material performance in nearly any engineering and/or science application, a vast amount of measurement methods and variations of those methods have been developed over many years. In spite of the number and variations that exits, these methods which are generally classified as being transient or steady - state. Steady - state measurements depends on precise measurement of heat flow and temperature and a well - controlled pattern of heat flow. Transient measurements have many advantage over steady - state, especially related measurement time and setup. Although simple in principles, steady - state measurement are generally quite complex in terms of system and setup. Transient measurement, on the other hand, often use a more complexly derived thermal conductivity based on the setup of the method. Transient measurements usually do not require as much efforts in terms of the setup and, relative to the steady - state type, are very quick to perform. In recent years, transient measurements have become much more common. For the purpose of measuring the thermal conductivity of clay-sand, available transient measurement methods are currently unable to perform the measurement needed due to physical structure and composition. For this reason, a steady - state measurement system based on the guarded - comparative - longitudinal heat flow technique has been designed, built, and analyzed to investigate its use for measuring clay-sand at high temperature [4]. The system has been used to measure the thermal conductivity of several samples.

Soil properties can be classified into two categories that are physical property and chemical property. The physical properties of soil are often the most important properties for evaluating the suitability of a soil for a particular purpose. Physical properties can be described with physical measurements such as length, mass, and temperature. These properties include texture, structure, bulk density, and porosity, the fraction of pore space in a soil. In turn these properties affect air water movement in the soil, and thus the soil's ability to function. Minerals and soil organic matter make up the solid fraction, whereas air and water comprise the pore space fraction. A typical agricultural soil is usually around $50.0 \%$ solid particles and $50.0 \%$ pores [1]. Soil structure is the arrangement and binding together of soil particles into large cluster, called aggregates. Aggregation is important for increasing stability against erosion, for maintaining porosity and soil water movement, and for improving fertility and carbon sequestration in the soil [3]. Adobe soils are soils with high clay content that swell and shrink dramatically and bare ground commonly has cracks in it in summer. An Adobe soil may be defined as a heavy soil which readily cracks, and certain adobe soils have not only high wilting and hygroscopic coefficients, but also high shrinkage coefficients. For example, some adobe soils shrink so much on drying that the air-dry volume is only half the volume of the moist soil. Adobe is a natural building material made from sand, clay, water, and some kinds of fibrous or organic material, which the builders shape into bricks (using frames), and dry in the sun. In hot climates, compared with the wooden buildings, adobe buildings offer significant advantages due to their greater thermal mass. Sharp sand, also known as builders' sand, refer to sand that has a gritty texture. This type of sand is often mixed with concrete for a number of different construction applications. Sharp sand can also be added to soil in order to create potting soil or to loosen clay soil. In most instances, this type of sand is made from ground quartz rock. On occasion, clay and iron may be mixed with quartz rock in order to create a sharper type of sand. Landscapers' construction workers may use these sharps as a base for lying pavement, mixing mortar, dressing lawns, and smoothing floors, [4]. 
This paper was aimed at determining the thermal conductivity for adobe (clay) mixed with Quartz (sand) using Lees Disc method.

\section{Materials and Methods}

\section{Design Method}

The method used in this paper was a Lee's Disc method for measuring thermal conductivity. The apparatus comprises of two metal disc, copper and brass, labeled B and C. The cylindrical slab of metal $\mathrm{C}$ of copper or brass, suspended by strings from a heavy stand on which a hollow cylinder $\mathrm{B}$ rest. The soil sample in a disc shape of the same diameter was placed between $\mathrm{B}$ and $\mathrm{C}$. Hole is bored near the bottom of cylinder $\mathrm{B}$ and another in $\mathrm{C}$ to hold two thermometers.

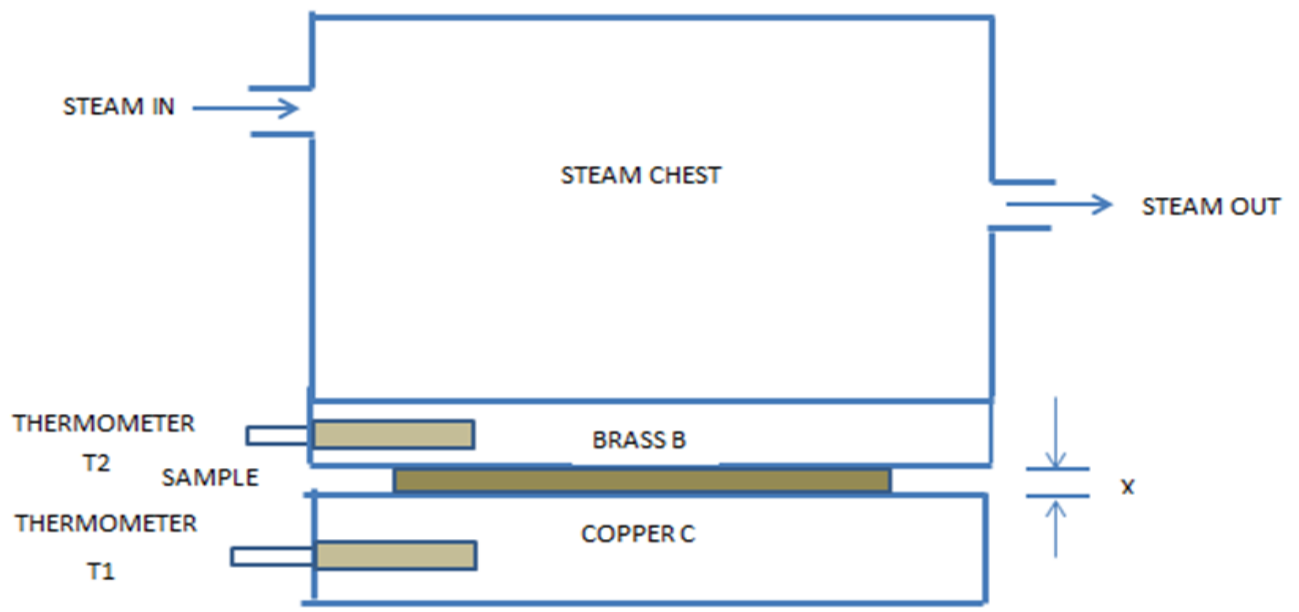

Figure 1: A Block Diagram of the Experimental Setup

\section{Sample Collection and Preparation}

The best undisturbed samples are those in which the soil water content and composition remain unchanged. But it is impossible to secure a completely undisturbed sample. The soil was carefully dug to an average depth of $50.0 \mathrm{~cm}$ from where the samples were collected. Each of the samples were collected in a reasonable quantity and dried thoroughly in the sun. The samples used were obtained in the size of $0.3 \times 0.3$ and $0.3 \times 0.5$ inches and about 8.0 inches long, there are 50 numbers of samples, (i.e.10 samples for each ratio), and were measured using Vernier/screw gauge, to about the same diameter of the Lee's disc i.e. $6.56 \mathrm{~cm}$ and $1.77 \mathrm{~cm}$ thickness. The surfaces of the samples were also smoothened for good thermal contacts. Each of the samples was obtained by mixed of Adobe soil (clay) with different proportions of Quartz (sharp sand) (i.e. 100:0, 95:5 and 80:20), and molded with a compression of $49 \mathrm{~N}$ in other to ensure conductivity of the particles of the samples, and to remove any trapped air. The samples were one after the other molded carefully removed from the mold and dried in the sun. They are now ready for testing using the Lee's disc method of determining the thermal conductivity of materials.

\section{Materials/Instruments}

The following materials/instruments were used for the purpose of this research.

- Two thermometers. 
- Stop clock.

- Weighing balance.

- Special clamp stand.

- Boiler

- Heater

- Vanier/Screw gauge

- Mold, and

- Lee's disc apparatus

\section{Procedure for Determining the Thermal Conductivity of the Sample (Adobe/Quartz)}

The block diagram is shown in Fig.1. A steam was passed through the cylinder B from a steam boiler and the temperature indicated by two thermometers, $\mathrm{T} 1$ and $\mathrm{T} 2$ as $\Theta 1$ and $\Theta 2$ were recorded when the steady state temperature has been reached. Cylinder B was now removed, C is still suspended. Heat $\mathrm{C}$ directly by the steam chamber, until $\mathrm{T} 2$ records the temperature up to $100 \mathrm{C}$ higher than that recorded in the steady state. Removed the steam chamber and wait for 2-3 minutes, so that heat is uniformly distributed over the disc and placed the insulating material on C. Start recording the temperature at interval of 30seconds is taking, using stop clock, continue till the temperature falls by $100 \mathrm{C}$ below the steady state temperature from $\mathrm{T} 1$. The samples were prepared by mixed of Adobe (clay) with different proportions of Quartz (sharp sand) (100:0, 95:5and 80:20), and then cut into proper shapes and sizes for thermal conductivity measurements.

\section{Results and Discussion}

The amount or quantity of heat, q, which is transmitted per second through a soil sample whose thickness is $\mathrm{x}$, can be determined by means of Fourier's Law.

$\mathrm{H}=$ rate of flow of heat

$\mathrm{K}=$ coefficient of thermal conductivity

$\mathrm{A}=$ cross sectional area of heat transfer

$\mathrm{T} 1=$ temperature at lower disc
Fourier's law : $q=\frac{k \cdot A \cdot\left(T_{H}-T_{C}\right)}{L}$

where

$q=$ heat transferred per unit time $(\mathrm{W})$

$A=$ heat transfer area $\left(\mathrm{m}^{2}\right)$

$\mathrm{k}=$ thermal conductivity of the material ( $\mathrm{W} / \mathrm{m} . \mathrm{K} 0$

$\mathrm{T}_{\mathrm{H}}=$ hot temperature $(\mathrm{K})$

$T_{c}=$ cold temperature $(K)$

$\mathrm{L}=$ material thickness $(\mathrm{m})$

$\mathrm{T} 2=$ temperature at upper disc

The manner of obtaining $\mathrm{T} 1$ and $\mathrm{T} 2$, the temperature of two points, merits some explanation. From steady state temperature readings, an average value was determined and used in calculations. The value of $\mathrm{K}$ was calculated from the temperature readings of both the upper and lower disc respectively. The result of this study is discussed using the variation of ratio of Adobe (clay soil) and Quartz (sand soil). Based on this variation, the following are the outcome of the research.

\section{Results of the Variation of Ratio 95:5 Adobes (Clay) to Quartz (Sand)}

This sample 1 contained ninety five percent Adobe (clay) and five percent Quartz (sand). The Time-temperature data obtained by recording the temperature at interval of 30.0 seconds, continued until the temperature falls by $100 \mathrm{C}$ below the steady state temperature from $\mathrm{T} 1$. 
Observed that (sample e) has the highest temperature of $83.80 \mathrm{C}$ at 0.0 second while (sample b) has lowest temperature of $45.50 \mathrm{C}$ at 1130 seconds.

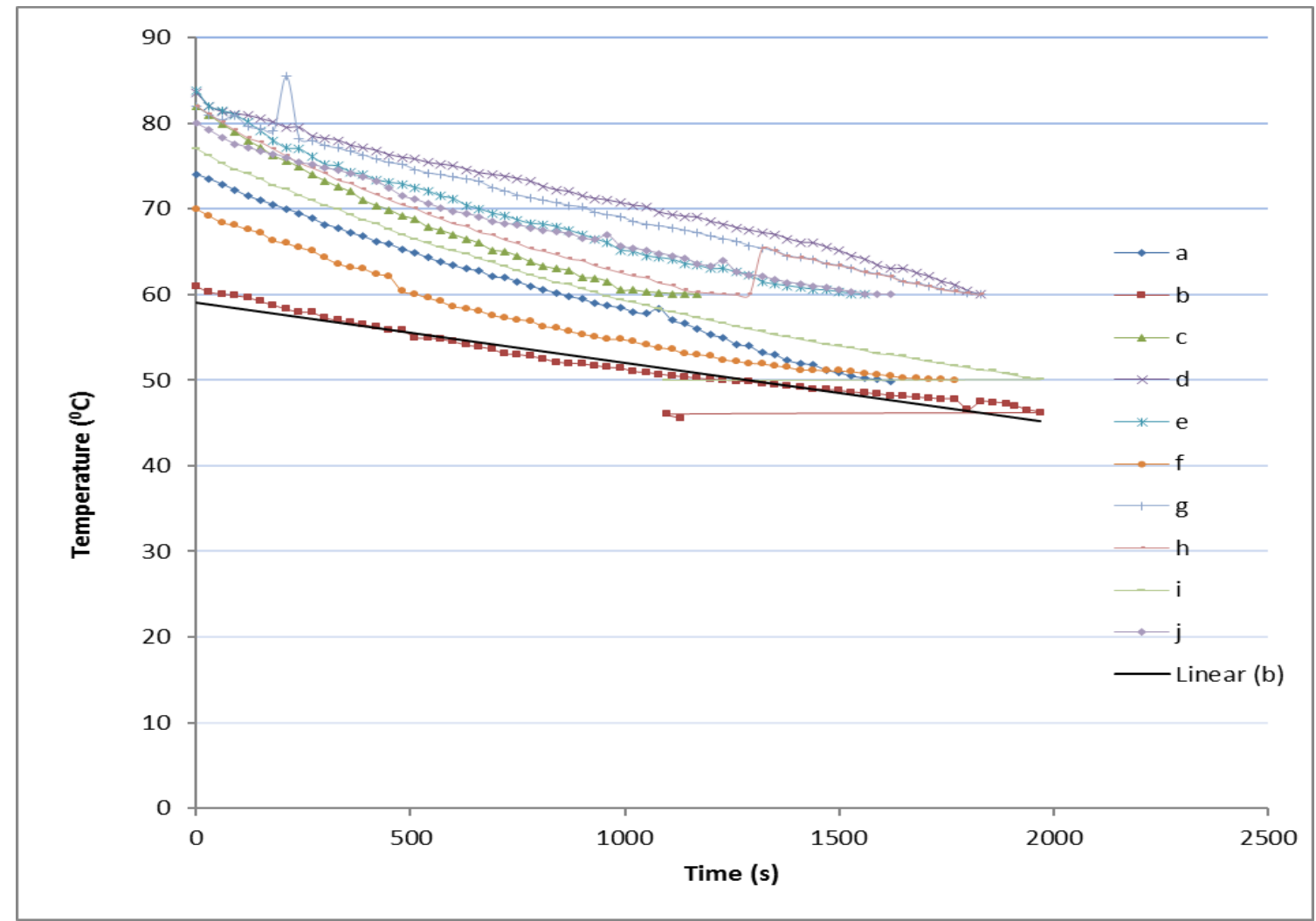

Figure 2: The cooling curve for sample $1(95: 5)$

The figure (2), gives the cooling rate with temperature of ten samples a-j, each of which having the same size but molded in different mold. It can be seen that (sample b) has the lowest thermal conductivity of $0.5330 \mathrm{Wm}-1 \mathrm{k}-1$ and the highest thermal conductivity of $1.3476 \mathrm{Wm}-1 \mathrm{k}-1$ for (sample h). This implies that sample b, produces the best result because of the lowest thermal conductivity which result in the high thermal resistivity that favors it as interior building materials for naturally cooled design in tropical region.

The figure (3), gives the cooling rate with temperature of ten samples a-j, each of which having the same size but molded in different mold. It can be seen that (sample b) has the lowest thermal conductivity of $0.2569 \mathrm{Wm}-1 \mathrm{k}-1$ and the highest thermal conductivity of $1.3820 \mathrm{Wm}-1 \mathrm{k}-1$ for (sample a). This implies that sample b, produces the best result because of the lowest thermal conductivity which result in the high thermal resistivity that favors it as interior building materials for naturally cooled design in tropical region.

\section{Result of the Variation of Ratio 100:0 Adobe (Clay) to Quartz (Sand)}

This sample contained hundred percent Adobe (clay) and zero percent Quartz (sand).

The Time-temperature data obtained by recorded the temperature at interval of 30.0 seconds, continue till the temperature falls by $100 \mathrm{C}$ below the steady state temperature from $\mathrm{T} 1$. Observed that (sample a) has the highest temperature of $80.00 \mathrm{C}$ at 0.0 second while (sample $\mathrm{h}$ ) has lowest temperature of $45.50 \mathrm{C}$ at 2100 seconds. 


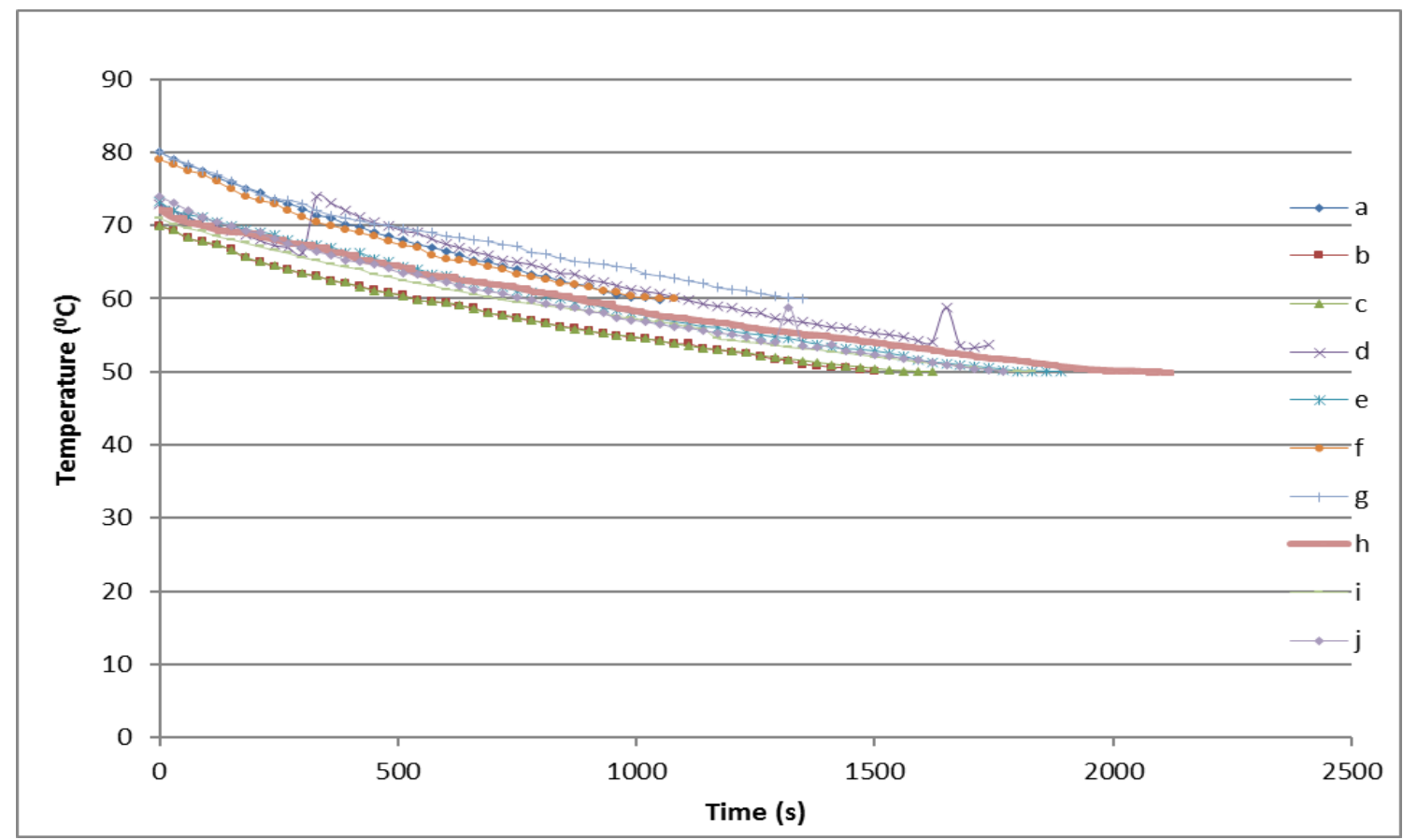

Figure 3: The cooling curve for sample 2 (100:0)

\section{Result of the Variation of Ratio 80:20 Adobe (Clay) to Quartz (Sand)}

This sample contained eighty percent Adobe (clay) and twenty percent Quartz (sand).

The Time-temperature data obtained by recorded the temperature at interval of 30 seconds, continue till the temperature falls by $100 \mathrm{C}$ below the steady state temperature from T1. Observed that (sample i) has the highest temperature of $80.00 \mathrm{C}$ at 0.0 second while (sample b) has lowest temperature of $40.50 \mathrm{C}$ at 24600 seconds.

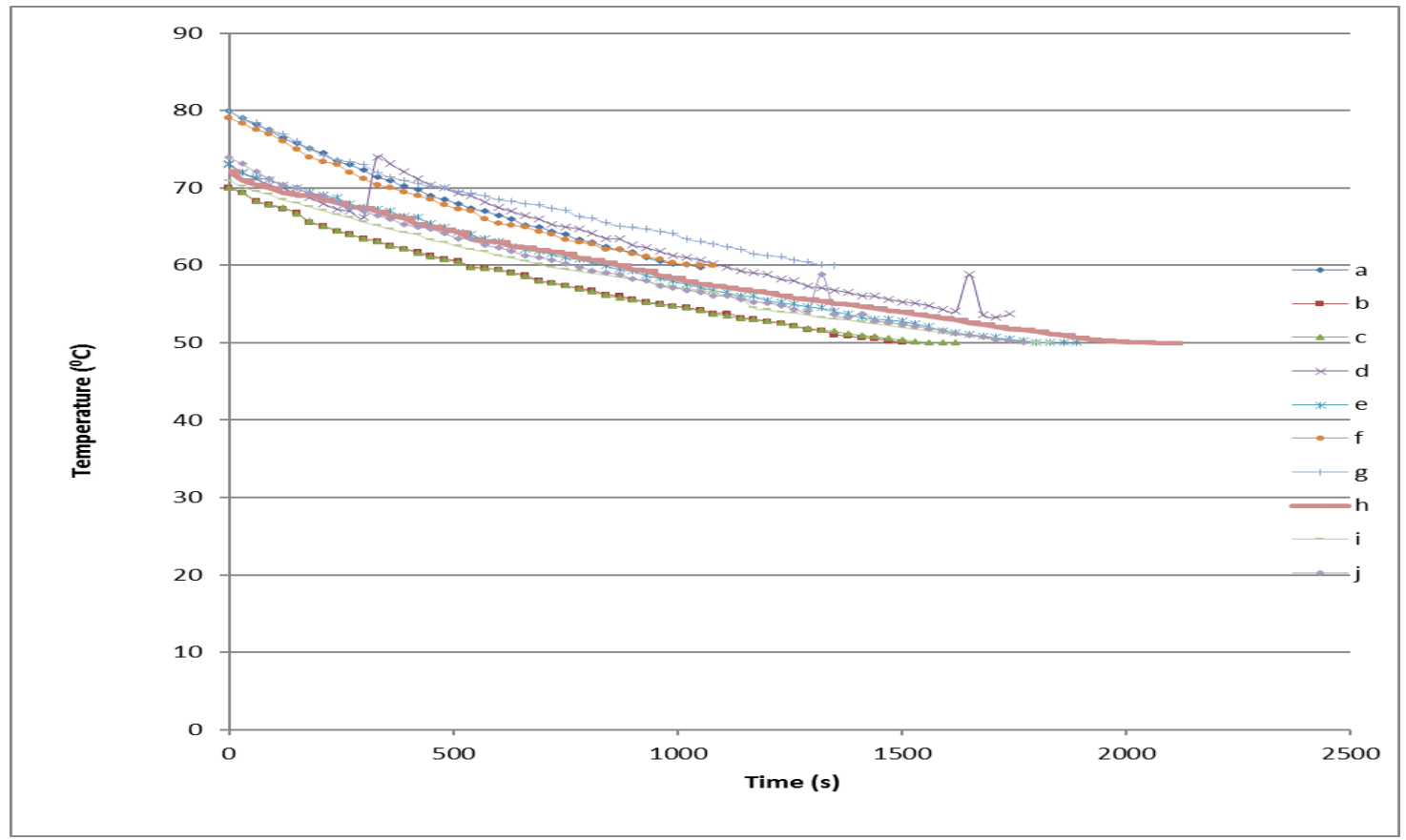

Fig 4: The cooling curve for sample 3 (80:20) 
The figure(4), gives the cooling rate with temperature of ten samples a-j, each of which having the same size but molded in different mold. It can be seen that (sample a) has the lowest thermal conductivity of $0.3212 \mathrm{Wm}-1 \mathrm{k}-1$ and the highest thermal conductivity of $0.9606 \mathrm{Wm}-1 \mathrm{k}-1$ for (sample i). This implies that sample a, produces the best result because of the lowest thermal conductivity which result in the high thermal resistivity that favours it as interior building materials for naturally cooled design in tropical region.

Table 1: Sample1 $1_{\mathrm{a}-\mathrm{j}}(95: 5)$ Parameters and Measured values

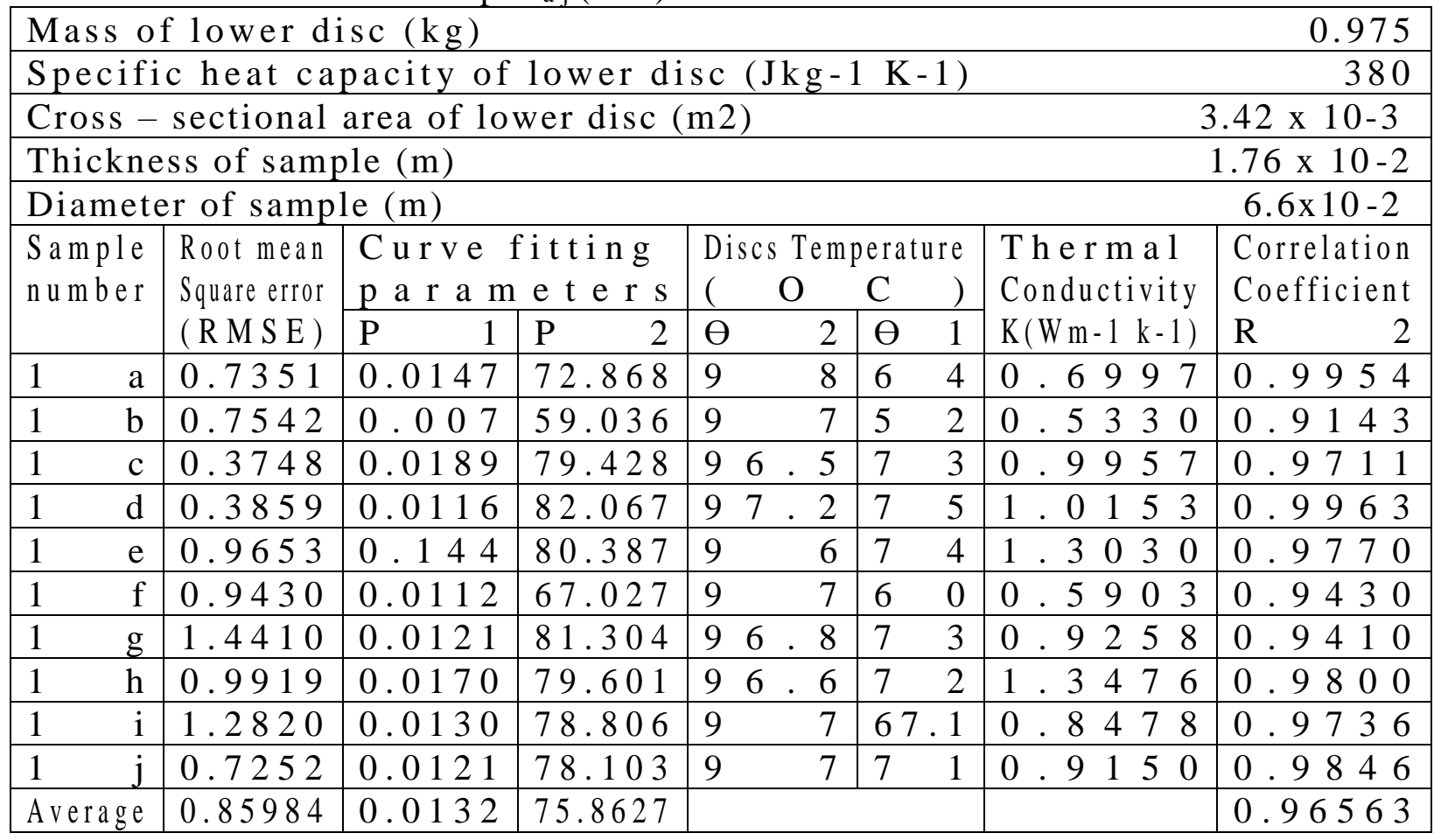

\begin{tabular}{|c|c|}
\hline M e a n & 0.91732 \\
\hline S T D E V & 0.270092 \\
\hline $\begin{array}{lll}\mathbf{V} & \mathbf{A} & \mathbf{R} \\
\end{array}$ & 0.07295 \\
\hline
\end{tabular}

Linear Model Polyol.

$\mathrm{K}(\mathrm{t})=\mathrm{P} 1 \mathrm{t}+\mathrm{P} 2 \ldots(2)$

where,

$\mathrm{K}=$ Thermal Conductivity

$\mathrm{t}=$ Ratio of Adobe to Quartz

$\mathrm{P} 1$ and $\mathrm{P} 2=$ Constant

Coefficient (with $95 \%$ confidence bounds)

$\mathrm{P} 1=-0.0132(-0.01175,0.01139)$ 
$\mathrm{P} 2=75.863(74237,75.897)$

$K(t)=-0.0132 t+75.8627 \ldots(3)$

Table 2: Sample 2a-j (100:0) Parameters and Measured values

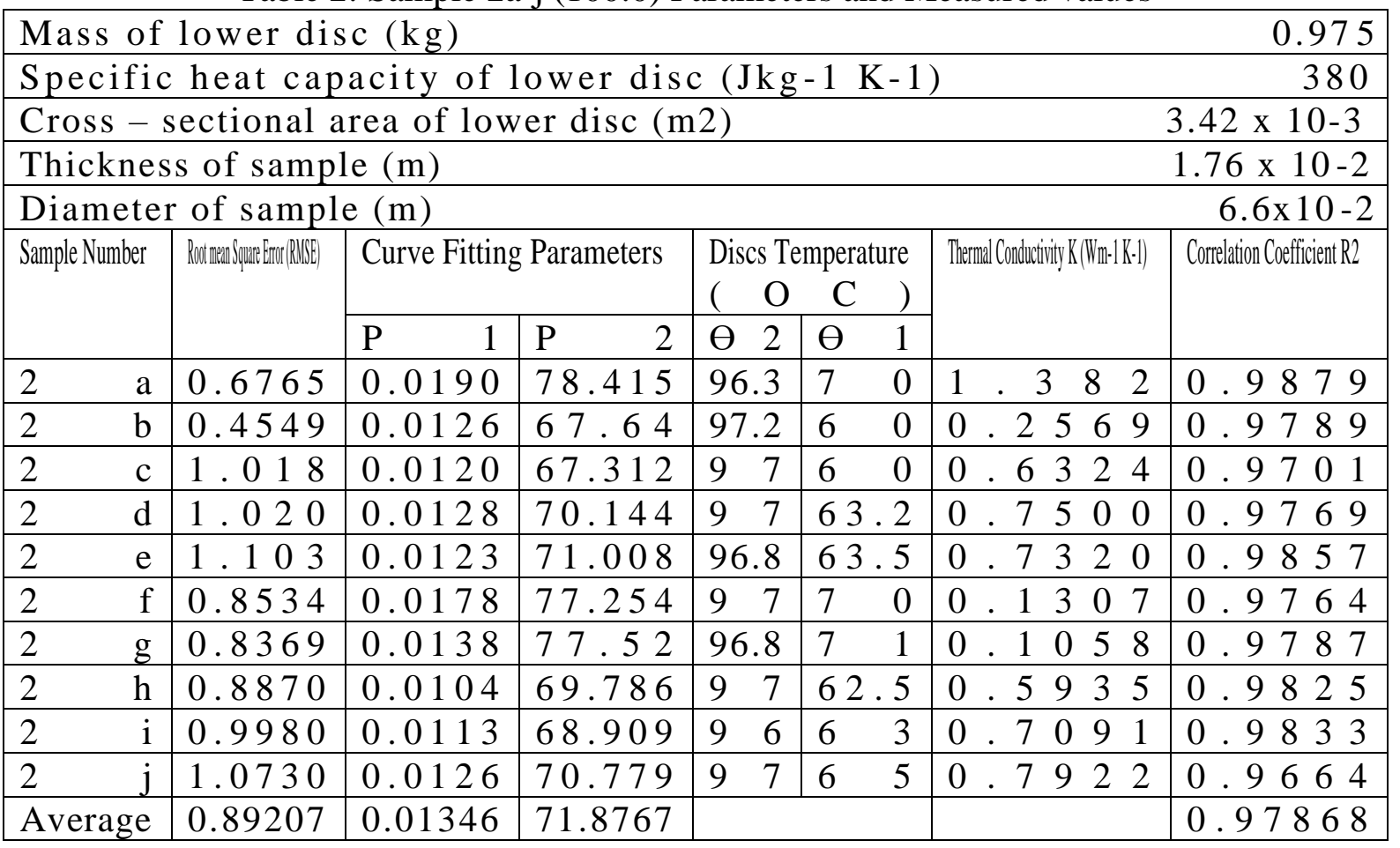

\begin{tabular}{|l|l|}
\hline M e a n & 0.60846 \\
\hline S T D E V & 0.377545 \\
\hline V A R . & 0.14254 \\
\hline
\end{tabular}

Linear Model Polyol.

$\mathrm{K}(\mathrm{t})=\mathrm{P} 1 \mathrm{t}+\mathrm{P} 2 \ldots(4)$

Where,

$\mathrm{K}=$ Thermal Conductivity

$\mathrm{t}=$ Ratio of Adobe to Quartz

$\mathrm{P} 1$ and $\mathrm{P} 2=$ Constant

Coefficient (with 95\% confidence bounds)

$\mathrm{P} 1=-0.0135(-0.012,-0.0198)$ 
$\mathrm{P} 2=71.877(70.97,71.91)$

SSE $=15.5602$

$\mathrm{K}(\mathrm{t})=-0.0135 \mathrm{t}+71.877 \ldots(5)$

Table 3: Sample3a-j(80:20) Parameters and Measured values

\begin{tabular}{|c|c|c|c|c|c|c|c|c|}
\hline \multicolumn{8}{|c|}{ Mass of lower disc $(\mathrm{kg})$} & 0.975 \\
\hline \multicolumn{9}{|c|}{ Specific heat capacity of lower disc $\left(\mathrm{Jkg}^{-1} \mathrm{~K}^{-1}\right)$} \\
\hline \multicolumn{8}{|c|}{ Cross - sectional area of lower disc $\left(\mathrm{m}^{2}\right)$} & $3.42 \times 10^{-3}$ \\
\hline \multicolumn{8}{|c|}{ Thickness of sample (m) } & $1.76 \times 10^{-2}$ \\
\hline \multicolumn{8}{|c|}{ Diameter of sample $(\mathrm{m})$} & $6.6 \times 10^{-2}$ \\
\hline \multirow[t]{2}{*}{ Sample Number } & \multirow[t]{2}{*}{ 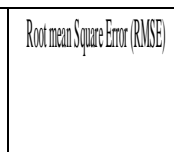 } & \multicolumn{2}{|c|}{ Curve Fitting Parameters } & \multicolumn{3}{|c|}{$\begin{array}{l}\text { Disc Temperature } \\
(\mathrm{O} C \mathrm{C}\end{array}$} & \multirow[t]{2}{*}{ Themal Conductinyty (Wmi'k') } & \multirow[t]{2}{*}{$\mid{\text { Correlation Coefficient } \mathrm{R}^{2}}^{2}$} \\
\hline & & $\mathrm{P}$ & $\mathrm{P}$ & $\theta$ & $\theta$ & & & \\
\hline 3 & 0.5200 & 0.008 & 53.27 & 9 & 4 & 6 & $\begin{array}{llll}3 & 2 & 1 & 2\end{array}$ & $9 \begin{array}{lll}9 & 7 & 3\end{array}$ \\
\hline 3 & 2.0370 & 0.0105 & 63.19 & 9 & 5 & 8 & 0.50500 & 94420 \\
\hline 3 & 1.5470 & 0.0117 & 64.42 & 9 & 5 & 9 & 61558 & $\begin{array}{llll}9 & 6 & 1 & 8\end{array}$ \\
\hline 3 & 0.78 .92 & 0.012 & 68.38 & 96.7 & 6 & 1 & 65553 & 98861 \\
\hline 3 & 0.6 & 0.0122 & 69.26 & 96. & 6 & 4 & 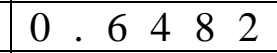 & 99 \\
\hline 3 & 1.0900 & 0.0125 & 69.48 & 9 & 6 & 3 & 7445 & $\begin{array}{llll}9 & 7 & 0 & 0 \\
\end{array}$ \\
\hline 3 & 1.1620 & 0.0121 & 70.57 & 96.2 & 6 & 6 & $\begin{array}{llll}7 & 9 & 4 & 2\end{array}$ & $\begin{array}{llll}9 & 6 & 8 & 3\end{array}$ \\
\hline 3 & 1.072 & 0.0118 & 71.71 & 9 & 6 & 5 & 0.744590 & 97730 \\
\hline 3 & 0.9849 & 0.0128 & 77.30 & & 7 & 0 & $\begin{array}{lllll}0 & .9 & 6 & 0 & 6\end{array}$ & $\begin{array}{llll}9 & 3 & 5 & 6\end{array}$ \\
\hline & 1.116 & 0.0113 & 76.12 & 96.5 & 7 & 1 & 0.68413 & $\begin{array}{llll}9 & 5 & 6 & 4 \\
\end{array}$ \\
\hline Average & 1.0978 & 0.01149 & 68.368 & & & & 0.684413 & 0.96559 \\
\hline
\end{tabular}

$K(t)=P 1 t+P 2 \ldots(6)$

\begin{tabular}{|c|c|}
\hline$M$ e a $n$ & 0.68413 \\
\hline$S$ T D E V & 0.180644 \\
\hline $\mathrm{V}$ A $\mathrm{R}$ & 0.032632 \\
\hline
\end{tabular}

Linear Model Polyl.

Where,

$\mathrm{K}=$ Thermal Conductivity

$\mathrm{t}=$ Ratio of Adobe to Quartz

$\mathrm{P} 1$ and $\mathrm{P} 2=$ Constant

Coefficient (with 95\% confidence bounds)

$\mathrm{P} 1=-0.01149(-0.0112,-0.01150)$

$\mathrm{P} 2=68.369(58.69,70.69)$ 
$\mathrm{SSE}=14.4967$

$\kappa(t)=-0.01149 t+68.369 \ldots(7)$

Table 4.: The Ratios of Adobe (Clay) to Quartz (Sharp sand) and average thermal conductivities.

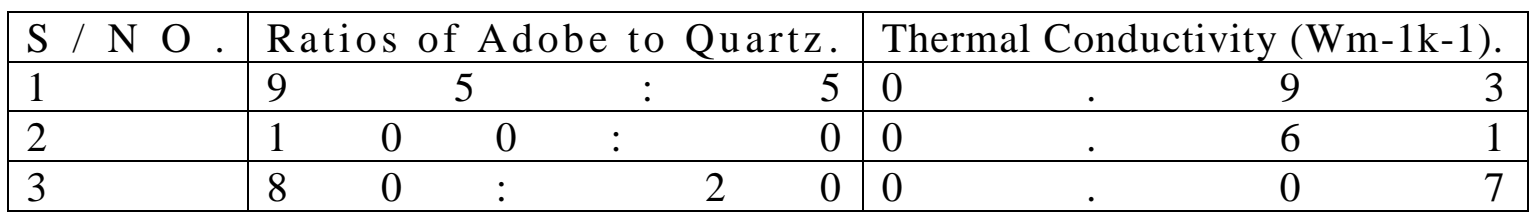

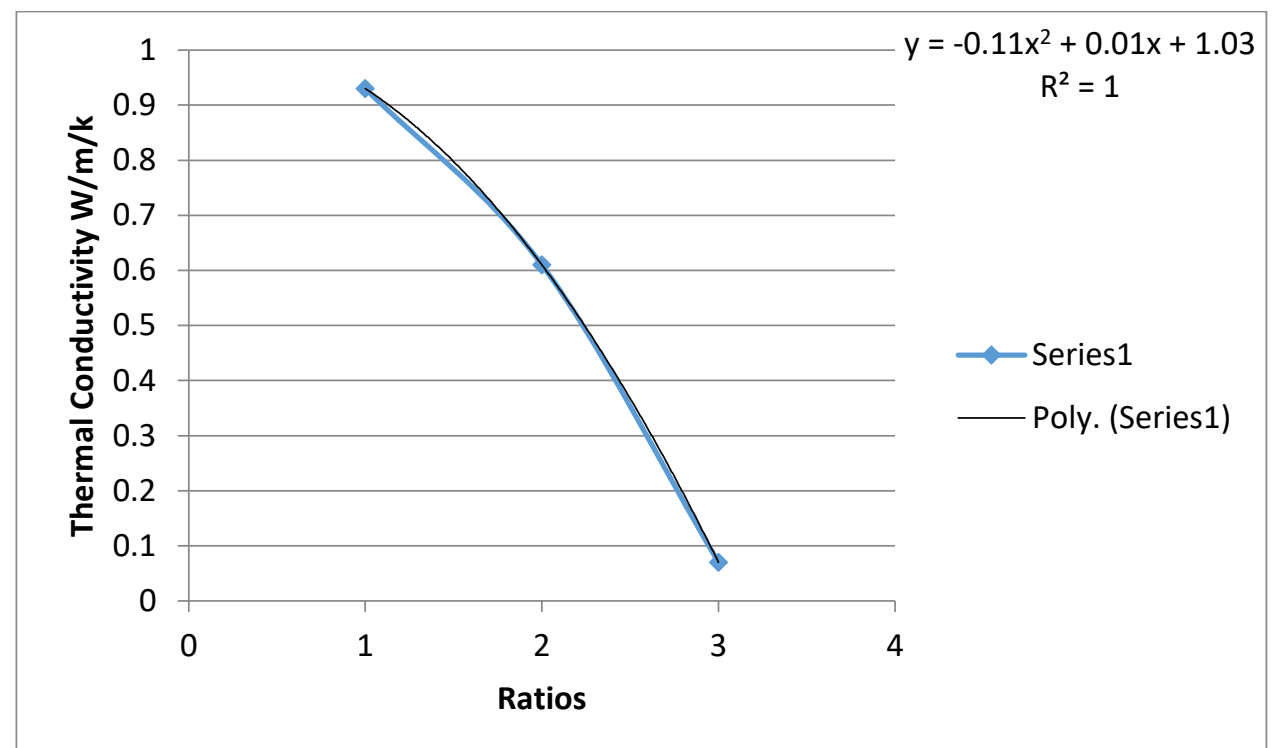

Fig 4: Graph of thermal conductivities against ratio of Adobe to Quartz

The average thermal conductivities of all the samples were calculated (See table 1, 2 and 3) and the graph was drawn against the ratios of Adobe to Quartz (See fig 4). It was observed that the sample contained the proportion of $(80: 20)$, has the average low thermal conductivity of $0.07 \mathrm{Wm}$ $1 \mathrm{~K}-1$, and sample of proportion (95:5), has the highest average thermal conductivity of $0.93 \mathrm{Wm}-$ 1K-1 .From the result obtained, Adobe/Quartz has low thermal conductivity, resulting in high thermal resistivity that favors it as interior building construction material for naturally cooled design.

The equation, $\mathrm{y}=-0.11 \mathrm{x} 2+0.01 \mathrm{x}+1.03$ is the general equation that can be used for the prediction of average thermal conductivity at various ratios. Where $y$ is the average thermal conductivity and $\mathrm{x}$ here signifies the ratios.

\section{Discussion}

In this study, a Lee's disc apparatus was used in the laboratory in order to choose a rational method by which thermal conductivity for an Adobe (clay)-Quartz (sand) can be estimated as a function 
of Adobe-Quartz ratios. Looking at the result of the thermal conductivities, which were calculated, (see table, 1, 2 and 3), there is a strong variation in the thermal conductivities of the samples. It was observed that sample1 (Adobe 95, Quartz 5 i.e. 95:5), has the highest thermal conductivity of 0.9173wm-1k-1, while sample5 (Adobe 90, Quartz 10 i.e. 100:0), has the least thermal conductivity of $0.60846 \mathrm{wm}-1 \mathrm{k}-1$. And the average thermal conductivity of all the samples were also calculated, the sample contained the proportion of $(80: 20)$, has the average lowest thermal conductivity of $0.07 \mathrm{Wm}-1 \mathrm{~K}-1$, and sample of proportion $(95: 5)$, has the average highest thermal conductivity of $0.93 \mathrm{Wm}-1 \mathrm{~K}-1$.Thermal conductivity varies principally with particles size distribution of soil, bulk density and the water content, the greater the bulk densityand the higher water content, the greater will be the thermal conductivity. The situation increases the effective inter-particles thermal contact within the soil [5]. The equation, $\mathrm{y}=-0.11 \mathrm{x} 2+0.01 \mathrm{x}+1.03$ is the general equation that can be used for the prediction of average thermal conductivity at various ratios. Where $\mathrm{y}$ is the average thermal conductivity and $\mathrm{x}$ here signifies the samples ratio.

The varying temperature regime within the soil effectively arises as consequences of soil surface temperature variation. The basic pattern of this variation is imposed by insulation and the way in which the net radiation of the soil surface separated by different layers. Soils in compacted condition have a greater thermal conductivity than the soil in a loose condition. Many processes occurring in the soil are greatly influenced by temperature. Kersten's thermal conductivity values were $0.9987,0.9946$, and $1.243 \mathrm{wm}-1 \mathrm{k}-1$ compared to thermal conductivities of $0.6841,0.6084$ and $0.9173 \mathrm{wm}-1 \mathrm{k}-1$ obtained in this study for temperature variation. In general, values obtained by [2] and [6] are higher than that obtained from the experiments described in this study. One explanation for these large differences could be because of using different procedure for measuring thermal properties.

\section{References}

[1] Brady and Weil, "Thermal properties of soil Adobe samples for a passively cooled". 16(4). 2002

[2] Kersten, M.S. “Thermal properties of soils."University of Minnesota Institute of Technology Engineering Experiment station, 11(21),1949.

[3] Nicholas, K.A, Wright S. F, Liebig, M A and Pikul Jr.J.L Functional Significance of glomalin to soil fertility. Proceedings from the Great Plains Soil Fertility Conference Proceedings.Denver, CO, March 2-4, 2004.

[4] Pillai, C; and George; A. "An improve comparative thermal conductivity of highly Radioactive specimens." Proc. International thermal conductivity conference 22, T.W. Tong, Ed. Techomic Publishing Company.1991.

[5] Rooyen V, Winterkorn. "Physical and Mechanical properties of particles" World Academy of Science, Engineering and Technology, 64,2010.

[6] Salomone, L.A., Kovacs, W.D., "Thermal properties of soils," Bulletin 28, Engineering Experiment Station, University of Minnesota, Minneapolis, Minn., 1949.

*Corresponding author.

E-mail address: snghshvkmr@ yahoo.co.in 